Mulemba

MULEMBA

Revista Angolana de Ciências Sociais

$5(10) \mid 2015$

Angola 40 anos de independência: memória, identidades, cidadania e desenvolvimento

\title{
Apresentação
}

\section{Virgílio Coelho}

\section{(2) OpenEdition}

12 Journals

\section{Edição electrónica}

URL: http://journals.openedition.org/mulemba/1703

DOI: $10.4000 /$ mulemba. 1703

ISSN: 2520-0305

Editora

Edições Pedago

\section{Edição impressa}

Data de publição: 1 novembro 2015

Paginação: 7-18

ISSN: 2182-6471

\section{Refêrencia eletrónica}

Virgílio Coelho, «Apresentação», Mulemba [Online], 5 (10) | 2015, posto online no dia 10 outubro 2018, consultado o 27 janeiro 2021. URL: http://journals.openedition.org/mulemba/1703 ; DOI: https:// doi.org/10.4000/mulemba.1703 


\section{Apresentação}

Este número, o décimo que o leitor tem em mãos, vem a público sob o símbolo das comemorações de mais um aniversário da Independência Nacional de Angola. Daí o seu título: Angola 40 anos da independência: Memória, Identidades, Cidadania e Desenvolvimento. Com efeito, essa questão específica reúne matérias que são fundamentalmente tratadas nas secções «Intervenções» e «Miscelânea», sendo resultantes do v Colóquio da Faculdade de Ciências Sociais da Universidade Agostinho Neto, que teve lugar na sede da FCS em Luanda, nos dias 29 e 30 de Outubro de 2015.

Em termos de estruturação, o fundamental das matérias que compõem este número estão organizadas em seis secções, a saber: (1) Artigos; (2) Projectos; (3) Intervenções; (4) Miscelânea; (5) Livros; (6) Documentos, que nos levam a viajar por inúmeros temas que tratam sobretudo de Angola, com a excepção de um ou outro texto.

A primeira secção, «Artigos» (pp. 19-321), é composta por oito trabalhos e esta abre com o texto «... E os meninos de há 40 anos, $o$ que aprenderam?...» (pp. 21-29), da socióloga Cesaltina Abreu que, ao utilizar como mote o refrão do poema «Os meninos do Huambo» de Manuel Rui (1976), «procura sintetizar uma retrospecção sobre o estado de satisfação relativamente às promessas da Dipanda dos que eram meninos(as) à data da independência há 40 anos». «O antes, o agora e o depois: Angola 40 anos depois» (pp. 31-51), da autoria da socióloga Ermelinda Liberato, é o texto que se alinha logo à seguir e no qual a autora procura fazer um balanço de 40 anos de independência de Angola marcado sobretudo por avanços e retrocessos. Nesse percurso indagador, a autora analisa os diferentes acontecimentos que marcaram cada época e de que forma estes influenciaram cada período assinalado. Segue-se-lhe o trabalho 
intitulado «Rethinking the 1961 Baixa de Cassange revolt: Towards a relational GeoHistory of Angola» (pp. 53-133), do geodemógrafo norte-americano Aharom de Grassi, um texto que é um capítulo da sua tese de doutoramento que defendeu recentemente na Universidade de Chicago, nos Estados Unidos da América (EUA). Trata-se, na realidade, de um estudo sobre a Baixa de Kassanje que aparece em boa hora, pois, o seu autor, através de uma reinterpretação geográfica e relacional do início da luta armada nacionalista em Angola, ajuda a criticar e ir além das interpretações comuns de Angola (e da África em geral), caracterizada por antigas divisões socio-espaciais. O texto seguinte, intitulado «Um álbum fotográfico da Diamang» (pp. 135-184), do historiador luso Diogo Ramada Curto, é o resultado de uma aturada pesquisa que deu azo a uma conferência lida e discutida com os seus colegas angolanos no Departamento de História (DH) da Faculdade de Ciências Sociais (FCS), e na qual o autor propõe uma longa discussão sobre a ideologia colonial, a partir da leitura da obra de José Osório de Oliveira, Flagrantes da vida na Lunda (1958), um álbum fotográfico encomendado pela Companhia de Diamantes de Angola (Diamang); segue-se-lhe o texto intitulado «A transculturação de Silva Porto na África Central Viyè - Século XIX», da autoria da historiadora Constança do Nascimento da Rosa Ferreira de Ceita, que constitui uma síntese da sua tese de doutoramento defendida na Faculdade de Ciências Sociais e Humanas (FCSH) da Universidade Nova de Lisboa (UNL) (pp. 185-232), e que ensaia uma explicação acerca da longa permanência na África central do sertanejo luso António Francisco Ferreira da Silva Porto, através do seu envolvimento no meio sociocultural ovimbundu (1839-1890). O artigo analisa o itinerário de interacção sociocultural entre o sertanejo e a sociedade ovimbundu, a história das relações sociais e transculturais operadas entre este e a referida sociedade no segundo quartel do século xIx; seguem-se os textos de dois sociólogos angolanos: Garcia Neves Quitari, « $A$ agricultura familiar em Angola: As armadilhas conceituais da classificação dicotómica» (pp. 233-260) e Joaquim Assis, «Práticas sociais e políticas das oNGs em Angola. Metodologias e relações de poder: o caso da ADRA e da Visão Mundial (World Vision)» (pp. 261-288). Através da sua reflexão, Quitari mostra que na análise acerca da agricultura familiar em Angola, geralmente se tem partido de falsas premissas, segundo a qual a agricultura 
familiar praticada na época colonial deve ser hoje o caminho a seguir. Esquecendo-se de interrogar a história, aqueles que tomam esse rumo parecem desconhecer ou ignorar que a agricultura familiar na época colonial assentara sobretudo na expropriação de terra dos africanos, no sistema de trabalho forçado, no monopólio colonial da produção e comércio dos produtos agrícolas, em detrimento dos africanos e da agricultura de subsistência. Contra esses argumentos, Quitari põe em causa esse raciocínio dicotómico e propõe uma forma real, actualizada, de lidar hoje com a agricultura familiar em Angola. Por sua vez, no seu texto, Joaquim Assis procura analisar as práticas políticas e sociais das ongs sediadas em Angola, discutindo a maneira como ocorrem as relações de poder entre os diferentes actores envolvidos nos processos sociais vigentes no meio rural, entre os anos 1990 e o ano de 2012; e, finalmente, encontramos o texto intitulado "As Ciências Sociais e a mudança ambiental global. Desafios para o desenvolvimento sustentável em África» (pp. 289-321) de dois autores lusos, já bem conhecidos entre nós: Nelson Lourenço e Carlos Russo Machado, texto esse apresentado por ocasião da Trienal UAN de $\mathrm{Hu}$ manidades - I Congresso 2014, um importante evento realizado em Luanda, no período de 11 a 18 de Abril de 2014, e organizado pelas Faculdades de Direito, de Economia, de Ciências Sociais e de Letras da Universidade Agostinho Neto (UAN). Com este texto, em que se parte de determinadas premissas acerca da mudança ambiental global, os autores propõem um novo quadro teórico e analítico multidisciplinar tendentes ao estudo de questões críticas para o desenvolvimento e a sustentabilidade global: segurança alimentar, segurança hídrica, segurança energética, segurança na saúde e segurança humana. Concomitantemente, e sempre de acordo com os autores, o quadro conceptual proposto deve produzir e integrar novos conhecimentos em áreas como governança e limites e limiares de mudança; uso sustentável do capital natural e conservação da biodiversidade; estilos de vida, ética e valores; implicações económicas das mudanças tecnológicas e sociais associadas à transição para economias com baixa intensidade de carbono, enquanto que, as estratégias de sustentabilidade deverão integrar as perspectivas e conhecimentos das ciências sociais na análise da mudança ambiental global e na definição de estratégias e políticas de desenvolvimento. 
«Projectos» (pp. 323-343), a segunda secção, propõe, em poucas linhas, o projecto de doutoramento em Ciências Sociais, na especialidade de Estudos Estratégicos, intitulado A (re)produção do poder político em Angola: uma estratégia de projecção externa (pp. 325-343) do investigador do Departamento de Ciência Política da FCs-UAN, Alberto Colino Cafussa, doutorando em Estudos Estratégicos no Instituto Superior de Ciências Sociais e Políticas (ISCSP) da Universidade de Lisboa. O referido trabalho em curso está a ser dirigido pelo Professor Doutor Heitor Romana e co-orientado pela Doutora Maria João Ferreira, no âmbito do Instituto Superior de Ciências Sociais e Políticas da Universidade de Lisboa (ISCSP-UL).

$$
* * * * *
$$

A terceira secção, «Intervenções» (pp. 345-741), é constituída por um conjunto de 18 textos, 16 dos quais foram apresentados por ocasião do $v$ Colóquio da Faculdade de Ciências Sociais da Universidade Agostinho Neto, que, conforme já anunciamos, teve lugar em Luanda nos dias 29 e 30 de Outubro de 2015.

O texto «Escola pública e democracia: Herança colonial, influência ocidental e património cultural endógeno», de Pedro Manuel Patacho (pp. 723-741), é incluído nesta secção porque embora o seu autor tenha estado ausente por razões alheias à sua vontade, no entanto, o mesmo foi preparado visando a sua participação nesse evento.

O primeiro texto, o único que não se relaciona com o aludido Colóquio, intitulado «José Maria Nunes Pereira: Professor, pesquisador, divulgador e animador das relações Brasil-África» (pp. 347-352), são palavras que foram proferidas pela professora Luena Nascimento Nunes Pereira, no Auditório principal da FCS-UAN, por ocasião do lançamento da obra de seu pai, José Maria Nunes Pereira, intitulada $O$ paradoxo angolano. Uma política externa em contexto de crise (1975-1994).

Luena Nascimento Nunes Pereira, antropóloga brasileira e professora da Universidade Federal Rural do Rio de Janeiro, República Federativa do Brasil, viajou para Angola a convite da FCS e da Editorial Kilombelombe, Lda., para testemunhar o lançamento da obra de seu pai, recentemente falecido, e orientar algumas conferências. Além deste texto de homenagem a seu pai, este número inclui ainda 
dois textos sobre a referida obra (cf. secção «Livros», infra) e uma nota necrológica onde se dá conta do percurso de vida de José Maria Nunes Pereira (cf. secção «Miscelânea - Necrologia», infra).

Em relação ao $v$ Colóquio da Faculdade de Ciências Sociais, impõe-se-nos que, no mínimo, expliquemos as suas razões temáticas, quais são as suas linhas de força e como as diversas matérias se articulam neste número.

Como se sabe, no dia 11 de Novembro de 2015 a República de Angola comemorou 40 anos desde a proclamação da sua Independência Nacional, por António Agostinho Neto (1922-1979), Presidente do Movimento Popular de Libertação de Angola (MPLA). É, com toda a certeza, uma data importante para os Angolanos, já que, a partir desse dia se assumiram como os condutores dos processos de direcção política e mudança revolucionária que se seguiram ao novel país independente.

Consciente da importância desta data histórica, a direcção da Faculdade de Ciências Sociais (FCS) da Universidade Agostinho Neto (UAN) propôs ao seu Conselho Científico-Pedagógico, que a organização do Colóquio de Ciências Sociais, um evento que se realiza anualmente durante o mês de Outubro, procurasse debater questões atinentes a essa importante data.

Assim, uma comissão organizadora foi prontamente indicada e em seguida nomeada, que trabalhou afincadamente na sua estruturação, tendo, finalmente, proposto que o v Colóquio de Ciências Sociais teria por tema Angola 40 anos de independência: Memória, Identidades, Cidadania e Desenvolvimento.

O documento orientador do v Colóquio de Ciências Sociais, que foi profusamente divulgado no âmbito da Faculdade e, em geral, da Academia Angolana, assim como junto dos órgãos da comunicação social, propunha nas suas linhas mestras o que se segue:

«Angola completa em Novembro de 2015 quarenta anos de país independente. Seja qual for a perspectiva científica ou o ângulo de análise, são evidentes as grandes transformações ao longo destas quatro décadas, na economia como na demografia, na política como na cultura. Na esfera pública ou na vida privada, vivemos hoje numa sociedade profundamente diferente daquela que em Novembro de 1975 celebrou a Independência. 
Por outro lado, o contexto internacional em África e no resto do mundo registou extraordinárias mudanças durante estas quatro décadas. Tais mundanças influenciaram decisivamente o evoluir da situação em Angola, mas também podemos afirmar que as mudanças em Angola influenciaram o mundo à nossa volta».

Entende-se, assim, que

«A FCS da UAN, através dos seus vários Cursos, está particularmente vocacionada para produzir e difundir conhecimento sobre a realidade social angolana e sobre o lugar de Angola no mundo actual. Cada uma das Ciências Sociais terá, portanto, contribuições específicas a dar para aprofundar o conhecimento do que é Angola hoje e de como se chegou até aqui. Mas compete também à Academia aplicar os seus instrumentos e capacidade de análise para ajudar a construir um futuro à altura das expectativas geradas pela proclamação da nossa Independência, em Novembro de 1975.

As últimas décadas merecem ser dissecadas com rigor, sem amalgamar as diferentes etapas que percorremos como país independente e sem escamotear as implicações, para o presente e o futuro, das opções feitas e dos processos em curso. Para entender o caminho percorrido, precisamos também de olhar para os tempos em que "independência" era um sonho e uma palavra perigosa. Seja pelo registo da memória individual ou colectiva, ou pelos resultados da investigação histórica, o passado precisa de ser trazido ao presente e analisado criticamente».

Deste modo, a Comissão Organizadora entendeu que estavam criadas as condições para que o $v$ Colóquio da Faculdade de Ciências Sociais da Universidade Agostinho Neto pudesse «celebrar os 40 anos da independência de Angola com uma grande abrangência temática, conjugando memórias, identidades, cidadania e desenvolvimento. A Antropologia, a Ciência Política, a Comunicação Social, a Geodemografia, a Gestão e Administração Pública, a História, a Psicologia e a Sociologia encontrarão campo para intervenções oportunas e fecundas. E o mesmo sucederá, certamente, com intervenientes vindos de outras disciplinas e áreas de conhecimento».

É com base nesta argumentação, que o v Colóquio da Faculdade de Ciências Sociais seria organizado com os objectivos seguintes:

- Promover uma ampla reflexão sobre as profundas transformações da sociedade angolana nos últimos quarenta anos; 
- Estimular a análise, fundamentada e crítica da situação actual, como instrumento útil para a definição de políticas futuras;

- Partilhar resultados da investigação histórica relacionada com os temas do Colóquio;

- Criar oportunidades de diálogo entre as gerações que testemunharam a luta pela independência e as que já nasceram no país independente.

Finalmente, visando atingir esses fins, o v Colóquio da Faculdade de Ciências foi estruturado em torno de cinco (5) painéis, que se basearam no seguinte quadro temático:

- Painel I - Memória(s), Identidades e a Nação em Construção;

- Painel II - Actores Políticos e Sociais e a Afirmação da Cidadania;

- Painel III - Instituições, Políticas Públicas e o Direito ao Futuro;

- Painel Iv - Os Caminhos do Desenvolvimento: Expectativas e Realidades;

- Painel Aberto.

Cada um dos Painéis e Temas tinham por fim:

\section{Painel 1 - Memória(s), Identidades e a Nação em cons- trução}

No eterno jogo da formação, consolidação, dissolução e recomposição de identidades, a memória social desempenha um papel determinante. Este painel abre-se à discussão sobre as relações entre memória e história, sobre o papel da literatura e da música na afirmação da angolanidade (no passado e no presente), e sobre o papel da(s) memória(s) na construção de identidades, nacionais e outras. Mas pretende igualmente questionar o uso (e abuso) do próprio conceito de «identidade», não só na academia como no discurso político ou na comunicação social.

\section{Painel 2 - Actores políticos e sociais e a afirmação da cidadania}

Num mundo complexo, onde a revolução tecnológica nas comunicações estreitou as relações entre o global e o local, os clássicos modelos de análise das Ciências Sociais são frequentemente desafiados pela emergência de novos (ou aparentemente novos) fenómenos 
e actores sociais. A afirmação da cidadania, nos seus múltiplos aspectos, obriga-nos à discussão sobre a redefinição dos limites do espaço público e das formas de participação política e cívica.

\section{Painel 3 - Instituições, políticas públicas e o direito ao futuro}

Um dos grandes desafios que se coloca a muitas sociedades africanas é o de reforçar instituições que, servindo os cidadãos, consolidem o Estado e lhe permitam desenhar e aplicar políticas públicas tendentes a satisfazer necessidades e aspirações da sua população, promovendo a inclusão social. No caso de Angola, os evidentes desequilíbrios, herdados do período colonial ou gerados no decorrer dos últimos 40 anos, precisam de ser enfrentados com políticas esclarecidas e instituições capazes de cumprirem o seu papel num mundo em mudança.

\section{Painel 4 - Os caminhos do desenvolvimento: Expectati- vas e realidades}

Em meados dos anos 1970, quando Angola se tornou independente, as receitas para o desenvolvimento dos países saídos dos antigos impérios coloniais pareciam claramente estabelecidas e o progresso, uma vez iniciado o caminho, seria irreversível. Nas últimas quatro décadas, essas ilusões desfizeram-se, mesmo em regiões do mundo mais estáveis que a nossa. Este painel abre-se a contribuições sobre a economia de Angola nos últimos quarenta anos, mas também sobre o desenvolvimento para lá dos indicadores económicos (o «desenvolvimento humano») e sobre a própria evolução de conceitos ou paradigmas relativos ao desenvolvimento.

Nesta conformidade, esta secção da revista integra os principais textos e conferências lidos e debatidos no referido colóquio, em função dos painéis e das temáticas. No entanto, não obstante os temas apresentados durante esse importante evento tenham suscitado discussões acaloradas, a coordenação da revista, movida pelo rigor que se exige, não poderia agir de outro modo a não ser efectuar uma rigorosa escolha dos textos que lhe foram submetidos. É da escolha parcimoniosa que foi efectuada, que nos permite ressaltar as suas múltiplas temáticas, desde «a emergência da Nação Angolana» (Kiamvu Tamu, pp. 353-373), e «a memória como matéria incendiária» (Maria da Conceição Neto, pp. 375-393), que constituíram 
conferências inaugurais do Colóquio, passando pela «diversidade étnica, etnicidade e processos de integração nacional em Angola» (Virgílio Coelho, pp. 395-426), «a identidade angolana e sua problemática» (Bortolami Gabriele, pp. 427-448), sobre «a proclamação da independência nacional e o seu primeiro reconhecimento pelo Brasil» (José Kalunsievo Nkosi, pp. 449-476), sobre «o manifesto do renascimento artístico-cultural angolano» (José Luís Mendonça, pp. 477-493), «participação política e cidadania» (Miguel Domingos Bembe, pp. 495-516), sobre os «objectivos da política externa angolana» (Aida Pegado, pp. 517-525), «a influência do serviço militar obrigatório e construção da cidadania» (António Guebe, pp. 527-547), «políticas educacionais e direito à educação» (Isaac Paxe, pp. 549-579), «gestão da água urbana» (Fernando Paulo Faria, pp. 581-599), «políticas públicas, instituições e direito ao bem-estar dos portadores de perturbações mentais» (Helena Veloso, pp. 601-614), o «movimento sindical em Angola» (Pedro de Castro Faria, pp. 615-628), «as flores da "Primavera Árabe": Que lições para Angola?» (Alberto Colino Cafussa, pp. 629-681), «reforma: uma politica de direito ao futuro» (João Saveia, pp. 683-703), «população e desenvolvimento em Angola» (Luiekakio Afonso, pp. 705-722), $\mathrm{e}$ «escola pública e democracia» (Pedro Manuel Patacho, pp. 723-741), enfim, um leque de temas que apresentados, discutidos e analisados durante os dois dias do Colóquio, permite-nos fazer conjugar a ideia geral sobre os 40 anos transcorridos na vida dos Angolanos e do seu País, 40 anos esses que, diga-se de passagem, não são mais do que uma gota de água perante a grandeza oceânica que constitui o diminuto capítulo da sua longa história, passado e presente confundidos.

Enfim, os participantes ao Colóquio deixaram claramente entender a necessidade de se continuar a abordar e discutir as múltiplas questões aí abordadas, muitas das quais, por virtude do tempo e do programa, não terão permitido maior possibilidade de discussão, não obstante o desejo evidenciado de o prolongar.

A secção «Miscelânea» (pp. 743-789) reproduz, na sua primeira parte, o comunicado final e o programa do $v$ Colóquio da Faculdade de Ciências Sociais, em que se explica, por um lado, a sua organização e, por outro, as ideias mestras do comunicado final (pp. 745-752). 
Na segunda parte desta secção encontramos informações sobre $\mathrm{Ne}$ crologia (pp. 753-789), em que são ressaltadas as mortes do Doutor Raúl Neto Fernandes, antigo Reitor da UAN (pp. 755-758); do docente de História de África Júlio Mendes Lopes (pp. 759-763); do professor zimbabweano Samson Moyo (pp. 765-770) e do professor e pesquisador brasileiro José Maria Nunes Pereira (pp. 771-789). Os professores e personalidades estrangeiras aqui repertoriados estabeleceram, de um ou de outro modo, relações estreitas com o nosso país e afigurou-se-nos justo que em momentos circunstanciais como é a ocorrência de suas mortes, que fosse estabelecido um último diálogo para com estes e ressaltado o importante papel por estes desempenhado seja no âmbito público, de formação, político ou outro.

$* * * \quad * * *$

A secção «Livros» (pp. 791-864) documenta a apresentação das seguintes obras: (1) Luanda. Estudo de Geografia Urbana, do geógrafo e historiador Ilídio do Amaral, lida pelo professor Luiekakio Afonso (pp. 793-807); (2) Manual prático de Demografia, do Eng. ${ }^{\circ}$ Manuel Félix, lida pelo professor Mingiedi Nzinga (pp. 809-815); (3) A gestão da doença no espaço sociocultural e urbano de Luanda. Os curandeiros tradicionais e os neotradicionais, da socióloga Fátima Vieigas, lida pelo professor José Octávio Serra Van-Dúnem (pp. 817-821); (4) O paradoxo angolano. Uma política externa em contexto de crise, de José Maria Nunes Pereira, recensão efectuada pelo jornalista Manuel Rodrigues Vaz (pp. 823-827); (5) O paradoxo angolano. Uma política externa em contexto de crise, de José Maria Nunes Pereira, prefácio a obra e apresentação pública efectuada por Manuel Inácio dos Santos Torres (pp. 829-839); e, finalmente, (6) La distintion. Critique sociale du jugement, do sociólogo francês Pierre Bourdieu, recensão da obra efectuada pela socióloga e Chefe do departamento de Sociologia, professora Cesaltina Abreu (pp. 841-864).

\section{*** $* * * *$}

Em «Documentação» (pp. 865-929), a última secção deste número, o leitor encontrará três documentos importantes, qualquer um deles com ligação directa à luta pela independência de Angola. 
O primeiro, intitulado «Acta da Fundação do Partido Comunista de Angola» (pp. 867-882) é um documento importante para a história não apenas da luta levada a cabo pelos Angolanos contra o colonialismo português, mas também, e sobretudo, para a compreensão da forma de surgimento das múltiplas instituições políticas, das suas ideias e tendências expressas por estes e cuja reprodução nos permite reflectir sobre a História contemporânea de Angola.

O segundo documento, denominado «Manifesto do Movimento Popular de Libertação de Angola» (pp. 883-916) é, certamente, um dos mais importantes documentos da luta política em prol da Independência Nacional criada pelos Angolanos. Trata-se, sobretudo, de um texto extraordinariamente bem escrito e digno de ser lido, cujas ideias mostram a clareza de quem o redigiu relativamente a caracterização da situação colonial e da luta a empreender, com os objectivos de se derrubar o colonialismo português e o imperialismo internacional que o suportava. Nos seus objectivos, extraordinariamente claros, o documento apresenta-se como um instrumento cujas linhas programáticas orientava para a necessidade de se lutar, sobretudo organizado, sob a orientação de um partido de vanguarda. Deste modo, tratando-se de um documento da luta clandestina, no entanto, o mesmo não foi encontrado nos arquivos da polícia colonial-fascista, a PIDE - Polícia Internacional e Defesa do Estado. Justamente por esse facto, esse documento tem-se apresentado para uns como a medida de todas as coisas e para outros exactamente o contrário. $\mathrm{O}$ facto dele ser para uns o indicativo das origens do Movimento Popular de Libertação de Angola (MPLA), nomeadamente sobre a data da fundação dessa estrutura política, e pelo facto, também, da data desse documento, não aparecer claramente no referido documento na letra de quem o redigiu, tem merecido clara desaprovação por quem tem rejeitado a criação ou o surgimento do MPLA em Dezembro de 1956. Ainda aqui, e sobretudo para aqueles que alegam o contrário, a antiguidade do documento tem sido posto em causa justamente por não ter sido encontrado nos arquivos da Torre do Tombo em Lisboa, como se esse facto constituisse a medida de tudo quanto fora feito durante a luta clandestina. Mas a PIDE não teve em mãos todos os documentos da luta armada e da luta clandestina e são hoje conhecidos alguns documentos importantes que nunca terão chegado nem por cheiro, ao conhecimento dessa temível polícia. Expressam-se, assim, múltiplas 
ideias contraditórias pelos mais variados posicionamentos, articulados no âmbito das ideias e da vontade política de determinados sectores, que se degladiam ainda hoje por aquilo que uns querem que o documento seja ou diga, tanto quanto por aquilo que outros expressem pelo contrário. Mas, em nosso modesto entender, é sem sombra de dúvida um documento muito importante para a história política contemporânea de Angola e é exactamente por isso que num momento como este o apresentamos aqui neste número comemorativo dos 40 anos da proclamação da independência nacional de Angola.

O terceiro, intitulado «Texto da proclamação da independência da República Popular de Angola» (pp. 917-929) é o documento que constitui a proclamação da Independência Nacional e projecta a criação da República Popular de Angola no concerto dos estados-nações. A avaliação da sua importância não cabe aqui dizê-lo, paira no coração de todos nós filhos desta pátria bem amada.

Com este breve dossier, relativo à passagem do $40 .^{\circ}$ aniversário da Independência de Angola, festejamos, igualmente, a edição do décimo número da Mulemba - Revista Angolana de Ciências Sociais, que desde o início da caminhada em 2011 nos propusemos fazer com vista contribuir para a melhoria e o aumento da informação científica e técnica dos nossos leitores, dos nossos professores, investigadores e alunos, sobretudo. Bem hajam, pois!

Virgílio Coelho

Editor 